\begin{tabular}{l|l|l|l}
$\begin{array}{l}\text { Case Reports in } \\
\text { Ophthalmology }\end{array}$ & $\begin{array}{l}\text { Case Rep 0phthalmol 2010;1:5-13 } \\
\text { D0I: } 10.1159 / 000313842\end{array}$ & Published online: May 12, 2010 & $\begin{array}{l}\text { @ 2010 S. Karger AG, Basel } \\
\text { ISSN 1663-2699 } \\
\text { www.karger.com/cop }\end{array}$ \\
\hline
\end{tabular}

\title{
Expression Profile of Intravitreous Cytokines, Chemokines and Growth Factors in Patients with Fuchs Heterochromic Iridocyclitis
}

\author{
Kaori Suzuki ${ }^{a}$ Yukihiko Suzuki $^{\mathrm{a}}$ Mitsuo Matsumoto ${ }^{\mathrm{b}}$ \\ Mitsuru Nakazawa ${ }^{a}$ \\ aDepartment of Ophthalmology, Hirosaki University Graduate School of Medicine, \\ and ${ }^{\mathrm{b}}$ Matsumoto Eye Clinic, Hirosaki, Japan
}

\section{Key Words}

Fuchs heterochromic iridocyclitis · Cytokines · Chemokines · Growth factors · Interleukins

\begin{abstract}
Purpose: To report the postoperative courses of 2 patients with Fuchs heterochromic iridocyclitis (FHI) and the concentrations of various cytokines, chemokines and growth factors in vitreous fluid samples to obtain insights into pathobiochemical aspects.

Subjects: The patients were a 27- and a 47-year-old woman. Phacoemulsification and aspiration, intraocular lens (IOL) implantation, and pars plana vitrectomy were performed to treat their cataracts and vitreous opacities. During their early postoperative periods, inflammatory cells precipitated on the IOL and intraocular pressure was increased in both patients.

Methods: At the time of surgery, undiluted vitreous fluid specimens were collected. The concentrations of multiple cytokines, chemokines and growth factors were measured by a bead array immunodetection system.

Results: The levels of interleukin-1 ra, $-5,-6,-8,-10$ and -13 , interferon-inducible 10-kDa protein, monocyte chemoattractant protein 1 , macrophage inflammatory protein $1 \beta$, and regulated upon activation, normal T-cell expressed and secreted (RANTES) were significantly elevated in vitreous fluid in both patients.

Conclusion: Although the postoperative course was generally favorable in patients with FHI, steroid instillation was necessary for a few months postoperatively, as precipitates easily formed on the IOL surface and elevated intraocular pressure. The profiles of intravitreal concentrations of cytokines, chemokines and growth factors may characterize postoperative inflammatory reactions.
\end{abstract}




\begin{tabular}{l|l|l|l}
$\begin{array}{l}\text { Case Reports in } \\
\text { Ophthalmology }\end{array}$ & $\begin{array}{l}\text { Case Rep 0phthalmol 2010;1:5-13 } \\
\text { Dol: } 10.1159 / 000313842\end{array}$ & Published online: May 12, 2010 & $\begin{array}{l}\text { ○ 2010 S. Karger AG, Basel } \\
\text { ISSN 1663-2699 } \\
\text { www.karger.com/cop }\end{array}$ \\
\hline
\end{tabular}

\section{Introduction}

Fuchs heterochromic iridocyclitis (FHI) is a kind of uveitis characterized by 3 major symptoms: heterochromia iridis, iridocyclitis and cataract [1]. Visual acuity is reportedly reduced in $96 \%$ of all FHI patients due to cataracts or vitreous opacity [2]. Although a number of independent reports regarding cataract surgery [3-7] and vitrectomy [8-10] procedures have been presented, relatively few have described combined vitrectomy and cataract surgery [11]. The usefulness of combination surgery is expected, as FHI reportedly causes not only cataracts but also vitreous opacity in $66-84 \%$ of the patients $[2$, $12]$.

As for intraocular cytokines, chemokines and growth factors that may modify inflammatory cell reactions and/or complications such as cataract, previous data reported by several investigators have proven somewhat ambiguous. Some researchers have reported that interferon (IFN)- $\gamma$ [13], interleukin (IL)-2 [14], and IL-10 [14] are increased in aqueous humor, and IL-2 is increased in vitreous fluid [15] in patients with FHI. Conversely, Curnow et al. [16] reported that IL-2, -12 and -13 were significantly decreased and IL-6 was no different in FHI aqueous humor compared to in noninflammatory aqueous humor. Excluding the multiplex bead array analysis by Curnow et al. [16] using aqueous humors and Banerjee et al. [17] using vitreous fluids, most previous studies have employed enzyme-linked immunosorbent assay (ELISA) with limited numbers of target proteins [12-15], so the exact profiles of cytokines, chemokines and growth factors distributed in vitreous fluid from patients with FHI have remained unclear.

We report herein 2 patients who underwent combined vitrectomy and cataract surgery for cataract and vitreous opacity associated with FHI. The concentrations of 27 different cytokines, chemokines and growth factors in vitreous fluid samples collected during vitrectomy were determined using a multiplex bead array immunodetection system (BioPlex ${ }^{\circledR}$; Bio-Rad, Hercules, Calif., USA) to obtain some insights into the pathobiochemical aspects of FHI.

\section{Subjects and Methods}

\section{Subjects}

Two female patients with FHI were referred to our clinic at the Hirosaki University Hospital in 2006, complaining of decreased visual acuity in the left eye, which showed cataracts and vitreous opacity. We performed combined phacoemulsification (PEA), pars plana vitrectomy (PPV) and intraocular lens (IOL) implantation in both patients, because vitreous opacity was gradually increased although an active inflammatory reaction was not clinically detected in either patient. After PEA, 3 scleral ports were prepared for PPV. A $0.3-\mathrm{ml}$ sample of undiluted vitreous fluid was collected before starting the PPV procedures with a 20 -gauge cutter connected to a 2.0 - $\mathrm{ml}$ syringe. Vitreous fluid was aspirated into the syringe by manually added suction pressure with a cutting rate of $400 \mathrm{cpm}$. The collected vitreous fluid was frozen and kept at $-80^{\circ} \mathrm{C}$ until bead array assay. Informed consent was obtained from each patient before surgery. This study was approved by the institutional committee of ethics and followed the tenets of the Declaration of Helsinki. Written and signed statements of the patients' informed consents were obtained to report their personal details and photographs.

\section{Methods}

The concentrations of 27 different cytokines, chemokines and growth factors in the vitreous fluid samples were simultaneously determined using a multiplex bead array immunodetection system (Bio- 


\begin{tabular}{l|l|l|l}
$\begin{array}{l}\text { Case Reports in } \\
\text { Ophthalmology }\end{array}$ & $\begin{array}{l}\text { Case Rep 0phthalmol 2010;1:5-13 } \\
\text { Dol: } 10.1159 / 000313842\end{array}$ & Published online: May 12, 2010 & $\begin{array}{l}\text { @ 2010 S. Karger AG, Basel } \\
\text { ISSN 1663-2699 } \\
\text { www.karger.com/cop }\end{array}$ \\
\hline
\end{tabular}

$\mathrm{Plex}^{\circledR}$; Bio-Lad) in accordance with the protocol set by the manufacturer. The immunodetection system contains bead-conjugated antibodies raised against 27 different cytokines, chemokines and growth factors as follows: interleukin-1 $\beta$ (IL-1 $\beta$ ), IL-1 receptor antagonist (IL-1ra), IL-2, IL-4, IL-5, IL-6, IL-7, IL-8 (chemokine C-X-C motif ligand (CXCL) 8), IL-9, IL-10, IL-12, IL-13, IL-15, IL-17, eotaxin (chemokine C-C motif ligand (CCL) 11), basic fibroblast growth factor (b-FGF), granulocyte-colony stimulating factor (G-CSF), granulocyte/macrophage-colony stimulating factor (GM-CSF), interferon (IFN)- $\gamma$, INF-inducible 10-kDa protein (IP-10, CXCL10), monocyte chemoattractant protein-1 (MCP-1, CCL2), macrophage inflammatory protein-1 (MIP-1 $\alpha, C C L 3)$, MIP-1 $\beta$ (CCL4), platelet-derived growth factor (PDGF-bb), regulated upon activation, normal T-cell expressed and secreted (RANTES, CCL5), tumor necrosis factor (TNF)- $\alpha$, and vascular endothelial growth factor (VEGF). As controls, vitreous fluids collected in a similar way from 23 eyes of patients with noninflammatory vitreoretinal diseases such as epiretinal membrane (ERM) or macular hole were used. Statistical analyses were performed by comparing each patient's data of the intravitreal substances to either 95 or $99 \%$ confidence interval for each control value.

\section{Case Reports}

\section{Case 1}

The patient was a 27-year-old woman who noticed decreased vision in the left eye in January 2006 and visited an ophthalmologist, who identified iridocyclitis and cataract and then referred her to our clinic. No family history or past illness was considered to have contributed to the condition.

At the first consultation, best-corrected visual acuity was 1.5 in her right eye (OD) and hand motion in her left eye (OS). Intraocular pressure was $15 \mathrm{~mm} \mathrm{Hg}$ OD and $12 \mathrm{~mm} \mathrm{Hg}$ OS. No abnormal findings were observed in the right eye. In the left eye, keratic precipitates, mild iridocyclitis, and a posterior subcapsular cataract were observed. The iris of the left eye was lighter in color than that of the right eye, demonstrating heterochromia. Moreover, the left eye displayed iris nodules. As for the anterior chamber angle, peripheral anterior synechia was observed in the left eye, but no obvious angle neovascularization was seen. Details of the retina could not be visualized due to vitreous opacity. No active vitreous inflammatory reaction was observed. Based on these findings, the patient was diagnosed with FHI associated with cataract and vitreous opacity in the left eye, for which combined vitrectomy and cataract surgery were planned.

PEA, PPV and IOL implantation were performed in April 2006. For IOL implantation, an acrylic IOL was inserted into the capsular bag. Amsler's sign with a slight hemorrhage was observed in the anterior chamber angle of the opposite side at the time of paracentesis, immediately after the start of surgery. At the time of the vitrectomy, the vitreous body and retina were found to adhere in some parts. Surgery was completed without any complication.

Visual acuity in the left eye was increased early after surgery, while intraocular pressure was normal at $18 \mathrm{~mm} \mathrm{Hg}$ and inflammation in the anterior chamber was mild under topical instillation of $0.1 \%$ fluorometholone. The retina showed no abnormalities. Intraocular pressure increased to $30 \mathrm{~mm} \mathrm{Hg} \mathrm{OS}$ at 16 days after surgery, but was lowered by instillation of $\beta$-blocker. Steroid instillation was suspended at about 1 month after surgery. However, at 2 months after surgery, pressure elevated again to $36 \mathrm{~mm}$ Hg OS. Accordingly, topical instillation of carbonic anhydrase inhibitor was added, since then intraocular pressure has been favorably maintained at $15 \mathrm{~mm} \mathrm{Hg}$. Cellular precipitates on the surface of the IOL as well as an aftercataract began to develop rapidly in the left eye (ig. 1). Visual acuity was not restored by YAG laser capsulotomy of the posterior capsule, due to heavy precipitation on the IOL surface, and visual acuity dropped to 0.5 . Administration of topical $0.1 \%$ fluorometholone was resumed at 3 months after surgery. Acuity in the left eye recovered to 1.2 until 5 months after surgery, as the precipitates on the IOL disappeared.

Since that time, the transparency of the IOL surface has been maintained and no elevation of intraocular pressure has been seen. As of 3 years after surgery, the patient has a visual acuity of 1.5 and intraocular pressure of $16 \mathrm{~mm} \mathrm{Hg}$ in the left eye without any treatment. 


\begin{tabular}{l|l|l|l}
$\begin{array}{l}\text { Case Reports in } \\
\text { Ophthalmology }\end{array}$ & $\begin{array}{l}\text { Case Rep 0phthalmol 2010;1:5-13 } \\
\text { Dol: } 10.1159 / 000313842\end{array}$ & Published online: May 12, 2010 & $\begin{array}{l}\text { @ 2010 S. Karger AG, Basel } \\
\text { ISSN 1663-2699 } \\
\text { www.karger.com/cop }\end{array}$ \\
\hline
\end{tabular}

Case 2

The patient was a 47-year-old woman with heterochromia, iridocyclitis, mild cataract, and vitreous opacity in the left eye since 2002. FHI was diagnosed. Visual acuity had been maintained at $1.0 \mathrm{OS}$, but dropped to 0.4 in 2004 along with the progression of posterior subcapsular cataract, which subsequently developed to mature cataract by 2006. Corrected visual acuity was $1.2 \mathrm{OD}$ and hand motion OS. Intraocular pressures were $16 \mathrm{~mm} \mathrm{Hg}$ OD and $14 \mathrm{~mm} \mathrm{Hg}$ OS. No abnormalities were identified in the right eye. In the left eye, keratic precipitates and mild iridocyclitis were observed. The left ocular fundus could not be visualized due to mature cataract. Iris atrophy and Koeppe nodules were observed in the iris of the left eye. No abnormal findings were seen for the chamber angle. No laboratory data indicated other granulomatous uveitis such as sarcoidosis or Harada disease.

PPV combined with PEA and IOL (acrylic IOL) implantation was performed in June 2006. Although opacity was found in the vitreous body, only lattice degeneration was seen in the retina. Unlike case 1, Amsler's sign was not seen during surgery. Postoperative inflammatory response was mild, visual acuity was 1.0 and intraocular pressure was $18 \mathrm{~mm} \mathrm{Hg}$ OS after surgery. However, intraocular pressure increased to $29 \mathrm{~mm} \mathrm{Hg}$ by 14 days after surgery, then lowered to $16 \mathrm{~mm} \mathrm{Hg}$ with the use of $\beta$-blocker eye drops. Although $0.1 \%$ fluorometholone administration was continued after surgery, white round precipitates started to form during the first postoperative month on the surface of the IOL, similar to those seen in Case 1 (fig. 2). Later, visual acuity was reduced in the left eye to 0.5 because of aftercataract, which was treated by YAG laser capsulotomy. Topical $0.1 \%$ fluorometholone instillation was continued until 2 years postoperatively. Visual acuity has remained at $1.2 \mathrm{OS}$ and intraocular pressure has been maintained at $10 \mathrm{~mm} \mathrm{Hg}$ without any eye drops.

\section{Results}

The concentrations of cytokines, chemokines and growth factors in vitreous fluid samples taken from Case 1 and 2 are summarized in table 1 . In comparison to the control group, the levels of IL-1 ra ( $\mathrm{p}<0.01,0.05$, respectively), IL-5 ( $<<0.01)$, IL-6 $(\mathrm{p}<0.01)$, IL8 (CXCL8, $\mathrm{p}<0.01$ ), IL-10 ( $\mathrm{p}<0.01)$, IL-13 ( $<<0.01,0.05$, respectively), IP-10 (CXCL10, $\mathrm{p}<0.01)$, MCP-1 (CCL2, p < 0.01), MIP-1 $\alpha$ (CCL3, p < 0.05), MIP-1 $\beta$ (CCL4, $p<0.01$ ), PDGF-bb $(\mathrm{p}<0.01)$ and RANTES (CCL5, $\mathrm{p}<0.01,0.05$, respectively) were significantly increased in the vitreous fluid of both FHI patients compared to those of patients with ERM. In addition, IL-2 (Case 2, p < 0.05), IL-12 (Case 2, p < 0.05), IL-17 (Case 2, $\mathrm{p}<$ 0.05 ), G-CSF (Case 2, p $<0.05$ ), IFN- $\gamma$ (Case 1, p $<0.05$ ), and VEGF (Case 1, p $<0.01$ ) were significantly increased in only 1 patient and did not appear of any significance in the other patient (table 1). Conversely, IL-1 $\beta$, IL-4, IL-7, IL-9, IL-15, eotaxin (CCL11), b-FGF, TNF- $\alpha$ and GM-CSF did not show any significant differences versus control samples.

\section{Discussion}

Iridocyclitis induced by FHI is characterized by mild inflammation of the anterior chamber, inflammation that does not become drastically aggravated, and an absence of peripheral anterior synechia, and is not curable by steroid therapy [18]. Moreover, steroid eye drops are not recommended to be administered to FHI patients over a long period, because of the possibility of glaucoma induced by FHI [3].

FHI-induced cataracts generally start with posterior subcapsular opacity, then quickly progress at some points [3]. In the present cases, cataracts progressed rapidly at a certain stage. Cataract surgery for FHI reportedly does not present unusual problems during the procedure, and postoperative inflammation is mild while the postoperative course is usually favorable [3-7]. In contrast, Javadi et al. [6] reported that the cause of poor vision in patients with postoperative visual acuity lower than $20 / 20$ was vitreous opacity. Furthermore, Waters et al. [8] reported that vitrectomy for vitreous opacity was effective 


\begin{tabular}{l|l|l|l}
$\begin{array}{l}\text { Case Reports in } \\
\text { Ophthalmology }\end{array}$ & $\begin{array}{l}\text { Case Rep 0phthalmol 2010;1:5-13 } \\
\text { D0I: } 10.1159 / 000313842\end{array}$ & Published online: May 12, 2010 & $\begin{array}{l}\text { (2010 S. Karger AG, Basel } \\
\text { ISSN 1663-2699 } \\
\text { www.karger.com/cop }\end{array}$ \\
\hline
\end{tabular}

for visual improvement in all cases analyzed, while cataracts were noted to progress at an early stage after the surgery. In view of these findings, benefits of combined vitrectomy and cataract surgery in FHI patients have been anticipated. Although Scott et al. [11] also noted that the results of pars plana lensectomy and PPV without IOL implantation were favorable, combined vitrectomy and cataract surgery with IOL implantation has rarely been reported.

In the present cases, combined vitrectomy and cataract surgery was chosen, as severe vitreous opacity and cataracts were associated. Although intense inflammatory responses are frequently observed after combined vitrectomy and cataract surgery for other types of uveitis, postoperative inflammatory responses were relatively mild in FHI, at least during the early postoperative period. In our patients, however, round precipitates began to develop abundantly on the surface of the IOL from about 2 weeks to 1 month after surgery, while postoperative inflammation was mild. The precipitates disappeared within a few months after administering steroid eye drops. Javadi et al. [6] reported deposition on the IOL in $26.8 \%$ of the examined FHI cases. Agrawal et al. [5] reported that precipitates were formed on the IOL surface after cataract surgery for FHI and that visual impairment resulted, for which the use of steroid eye drops after surgery was recommended. Also, the elevation of intraocular pressure commonly observed in our patients could be controlled by topical instillation of $\beta$-blockers and carbonic anhydrase inhibitors.

Previous studies have investigated the intraocular concentrations of multiple cytokines, chemokines and growth factors in patients with uveitis, noting that IL-6, IL-8, IL-10, IL12 , IP-10, MCP-1, RANTES, MIP-1 $\alpha$, MIP-1 $\beta$, and IFN- $\gamma$ are present at high concentrations in aqueous humor [16, 19, 20]. Also, Banerjee et al. [17] reported cytokines, chemokines and growth factors in the vitreous fluid of various vitreoretinal diseases and showed that IL-6, MCP- 1 and IL- 8 were increased, while MIP- $1 \alpha$, MIP- $1 \beta$, RANTES, eotaxin and IL-8 were not elevated in the vitreous fluid from patients with chronic uveitis. The levels of cytokines such as IFN- $\gamma$ and chemokines such as RANTES, IP-10, MCP-1, and MIP-1 $\alpha$ were also reportedly elevated in experimental autoimmune uveitis (EAU) mice $[18,21,22]$. In the present study, IL-1 ra, IL-5, IL-6, IL-8, IL-10, IL-13, IP-10, MCP-1, MIP-1 $\alpha$, MIP-1 $\beta$, PDGF-bb and RANTES were shown to increase in vitreous fluid at significantly high concentrations in both patients with FHI. However, IFN- $\gamma$ was only slightly elevated in just 1 patient $(\mathrm{p}<0.05)$. This result may indicate that FHI does not have an autoimmune nature, unlike EAU. In addition, most chemokines examined in the present study were increased in the vitreous fluid. Because MIP-1, MCP1 and IP-10 play a role in the initial recruitment of inflammatory cells into the eye and IL8 activates and attracts neutrophiles [16]. Increased levels of these chemokines in the vitreous fluid may suggest that inflammatory reaction can be easily initiated using the vitreous cavity in our patients. Cellular precipitation on the IOL surface in the early postoperative period can be partially explained by the increased concentrations of these chemokines. Also, it should be noted that topical instillation of steroid eye drops is effective to treat cellular precipitation on the IOL. As for growth factors, the concentration of VEGF was elevated in Case 1 but not in Case 2. This result may explain the phenomenon that Amsler's sign occurred only in Case 1, because neovascularization might have been induced in the chamber angle by an increased concentration of VEGF, although it was not observed by a preoperative gonioscopic examination.

In conclusion, the present results suggest: first that various kinds of inflammatory cytokines and chemokines are elevated in the vitreous fluid of patients with FHI, second that postoperative inflammatory reactions may be related to these increased levels of 


\begin{tabular}{l|l|l|l}
$\begin{array}{l}\text { Case Reports in } \\
\text { Ophthalmology }\end{array}$ & $\begin{array}{l}\text { Case Rep 0phthalmol 2010;1:5-13 } \\
\text { Dol: } 10.1159 / 000313842\end{array}$ & Published online: May 12, 2010 & $\begin{array}{l}\text { @ 2010 S. Karger AG, Basel } \\
\text { ISSN 1663-2699 } \\
\text { www.karger.com/cop }\end{array}$ \\
\hline
\end{tabular}

cytokines and chemokines, and third that topical instillation of steroid eye drops is effective to control postoperative inflammation and cellular precipitates on the IOL surface. Attention is also required in case of elevation of intraocular pressure during the early postoperative period.

Table 1. Intravitreous concentrations of cytokines, chemokines and growth factors in Fuchs heterochromic iridocyclitis

\begin{tabular}{lccc}
\hline & Control & Case 1 & Case2 \\
\hline IL-1 $\beta$ & $28.28 \pm 20.79$ & 57.5 & 66 \\
IL-1ra & $44.30 \pm 29.04$ & $242^{* *}$ & $112^{*}$ \\
IL-2 & $39.28 \pm 19.70$ & 61 & $125^{*}$ \\
IL-4 & $53.33 \pm 41.19$ & 111 & 154 \\
IL-5 & $16.26 \pm 13.59$ & $247.5^{* *}$ & $250^{* *}$ \\
IL-6 & $188.24 \pm 167.78$ & $2,111.5^{* *}$ & $1,874^{* *}$ \\
IL-7 & $51.83 \pm 37.58$ & 72 & 74 \\
IL-8 (CXCL8) & $193.61 \pm 164.04$ & $4,118^{* *}$ & $1,773^{* *}$ \\
IL-9 & $251.43 \pm 172.11$ & 494.5 & 529 \\
IL-10 & $30.22 \pm 22.64$ & $874^{* *}$ & $483^{* *}$ \\
IL-12 & $33.89 \pm 23.94$ & 64 & $82^{*}$ \\
IL-13 & $24.98 \pm 21.14$ & $84^{*}$ & $120.5^{* *}$ \\
IL-15 & $1,121.89 \pm 282.14$ & 1,101 & 441.5 \\
IL-17 & $154.52 \pm 117.99$ & 290.5 & $32,050^{* *}$ \\
IP-10 (CXCL10) & $1,166.39 \pm 1,589.52$ & $30,633^{* *}$ & 97 \\
Eotaxin (CCL10) & $44.41 \pm 34.54$ & 79 & 775 \\
b-FGF & $395.91 \pm 276.74$ & 576 & $113^{*}$ \\
G-CSF & $37.76 \pm 27.90$ & 89 & 79 \\
IFN- $\gamma$ & $31.35 \pm 24.16$ & $85^{*}$ & $30,094^{* *}$ \\
MCP-1 (CCL2) & $4,167.85 \pm 3,503.73$ & $16,050^{* *}$ & $145^{*}$ \\
MIP-1 $\alpha$ (CCL3) & $41.98 \pm 32.35$ & $110^{*}$ & $3,940.5^{* *}$ \\
MIP-1 $\beta$ (CCL4) & $358.02 \pm 336.57$ & $2,583.5^{* *}$ & $158^{* *}$ \\
PDGF-bb & $35.30 \pm 29.48$ & $126.5^{* *}$ & $1,032^{*}$ \\
RANTES (CCL5) & $171.93 \pm 289.71$ & $4,927^{* *}$ & 415.5 \\
TNF- $\alpha$ & $158.11 \pm 106.52$ & 274 & 731 \\
VEGF & $215.17 \pm 201.52$ & $1,068.5^{* *}$ & 689 \\
GM-CSF & $415.78 \pm 318.96$ & & \\
\hline & & & \\
\hline
\end{tabular}

All values are expressed in picogram/milliliter. ${ }^{*} \mathrm{p}<0.05 ;{ }^{*} \mathrm{p}<0.01$. 


\begin{tabular}{l|l|l|l}
$\begin{array}{l}\text { Case Reports in } \\
\text { Ophthalmology }\end{array}$ & $\begin{array}{l}\text { Case Rep 0phthalmol 2010;1:5-13 } \\
\text { D0I: } 10.1159 / 000313842\end{array}$ & Published online: May 12, 2010 & $\begin{array}{l}\text { ○ 2010 S. Karger AG, Basel } \\
\text { ISSN 1663-2699 } \\
\text { www.karger.com/cop }\end{array}$ \\
\hline
\end{tabular}

Fig. 1. Case 1. Left eye at 2 months after surgery. Precipitates were formed on the IOL surface (arrow).

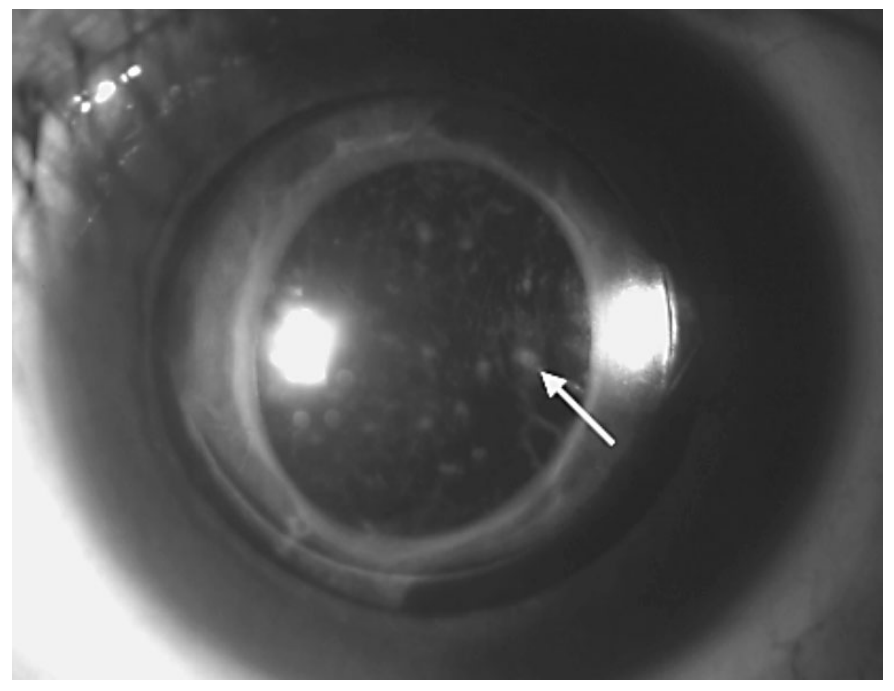

Fig. 2. Case 2. Left eye at 1 month after surgery. Precipitates were formed on the IOL surface.

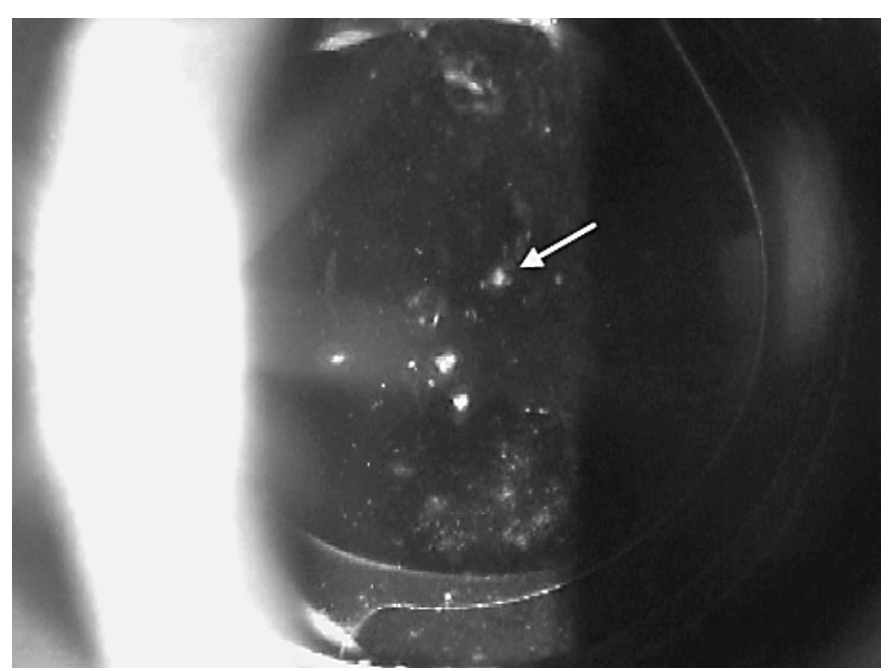




\begin{tabular}{l|l|l|l}
$\begin{array}{l}\text { Case Reports in } \\
\text { Ophthalmology }\end{array}$ & $\begin{array}{l}\text { Case Rep 0phthalmol 2010;1:5-13 } \\
\text { D0I: } 10.1159 / 000313842\end{array}$ & Published online: May 12, 2010 & $\begin{array}{l}\text { (2010 S. Karger AG, Basel } \\
\text { ISSN 1663-2699 } \\
\text { www.karger.com/cop }\end{array}$ \\
\hline
\end{tabular}

\section{References}

1 Fuchs E: Ueber Komplicationen der Heterochromie. Z Augenheilkd 1906;15:165176.

-2 Fearnley IR, Rosenthal AR: Fuchs' heterochromic iridocyclitis revisited. Acta Ophthalmol Scand 1995;73:166-170.

3 Ariga T, Kotake S, Sasamoto Y: Clinical features of Fuchs heterochromic iridocyclitis. Rinsho Ganka (Jpn Clin Ophthalmol) 2000;54:1779-1783.

-4 Ram J, Kaushik S, Brar GS, Gupta A, Gupta A: Phacoemulsification in patients with Fuchs' heterochromic uveitis. J Cataract Refract Surg 2002;28:1372-1378.

$\checkmark 5$ Agrawal S, Agrawal J, Agrawal TP: Concern about long-term results of IOL implantation in Fuchs' heterochromic uveitis. J Cataract Refract Surg 2003;29:1469-1470.

-6 Javadi MA, Jafarinasab MR, Araghi AS, Mohammadpour M, Yazdani S: Outcomes of phacoemulsification and in-the-bag intraocular lens implantation in Fuchs' heterochromic iridocyclitis. J Cataract Refract Surg 2005;31:997-1001.

7 Budak K, Akova YA, Yalvac I, Somer D, Aslan BS, Duman S: Cataract surgery in patients with Fuchs' heterochromic iridocyclitis. Jpn J Ophthalmol 1999;43:308311.

-8 Waters FM, Goodall K, Jones NP, McLeod D: Vitrectomy for vitreous opacification in Fuchs' heterochromic uveitis. Eye 2000;14:216-218.

$\checkmark 9$ Mohamed O, Zamir E: Update on Fuchs' uveitis syndrome. Curr Opin Ophthalmol 2005;16:356-363.

10 Velilla S, Dios E, Herreras JM, Calonge M: Fuchs' heterochromic iridocyclitis: a review of 26 cases. Ocul Immunol Inflamm 2001;9:169-175.

11 Scott RA, Sullivan PM, Aylward GW, Pavésio CE, Charteris DG: The effect of pars plana vitrectomy in the management of Fuchs heterochromic cyclitis. Retina 2001;21:312-316.

12 Jones NP: Fuchs' heterochromic uveitis: a reappraisal of the clinical spectrum. Eye 1991;5:649-661.

13 Lacomba MS, Martin CM, Chamond RR, Galera JM, Omar M, Estevez EC: Aqueous and serum interferon gamma, interleukin (IL) 2, IL-4, and IL-10 in patients with uveitis. Arch Ophthalmol 2000;118:768-772.

14 Muhaya M, Calder V, Towler HM, Shaer B, McLauchlan M, Lightman S: Characterization of phenotype and cytokines in the aqueous humor $(\mathrm{AH})$ in patients with Fuchs' heterochromic cyclitis (FHC) and idiopathic anterior uveitis (IAU). Clin Exp Immunol 1998;111:123-128.

15 Ongkosumito JV, Feron EJ, van Doomik, Van der Lelij A, Hoyng CB, La Heij EC, Kilstra A: Analysis of immunoregulatory cytokines in ocular fluid samples from patients with uveitis. Invest Ophthalmol Vis Sci 1998;39:2659-2665.

16 Curnow SJ, Falciani F, Durrani OM, Cheung CMG, Ross EJ, Wloka K, Rauz S, Wallace GR, Salmon M, Murray PI: Multiplex bead immunoassay analysis of aqueous humor reveals distinct cytokine profiles in uveitis. Invest Ophthalmol Vis Sci 2005;46:4251-4259.

$>17$ Banerjee S, Savant V, Scott RAH, Curnow SJ, Wallace GR, Murray PI: Multiplex bead analysis of vitreous humor of patients with vitreoretinal disorders. Invest Ophthalmol Vis Sci 2007;48:2203-2207.

18 Crane IJ, McKillop-Smith S, Wallace CA, Lamont GR, Forrester JV: Expression of the chemokines MIP-1 alpha, MCP-1, and RANTES in experimental autoimmune uveitis. Invest Ophthalmol Vis Sci 2001;42:1547-1552.

19 Verma MJ, Lloyd A, Rager H, Strieter R, Kunkel S, Taub D, Wakefield D: Chemokines in acute anterior uveitis. Curr Eye Res 1997;16:1202-1208.

20 Ooi KGJ, Galatowicz G, Calder VL, Lightman SL: Cytokines and chemokines in uveitis. Is there a correlation with clinical phenotype? Clin Med Res 2006;4:294309.

-21 Keino H, Takeuchi M, Kezuka T, Yamakawa N, Tsukahara R, Usui M: Chemokine and chemokine receptor expression during experimental autoimmune uveoretinitis in mice. Graefes Arch Clin Exp Ophthalmol 2003;241:111-115.

22 Sonoda K, Sasa Y, Qiao H, Tsutsumi C, Hisatomi T, Komiyama S, Kubota T, Sakamoto T, Kawano Y, Ishibashi T: Immunoregulatory role of ocular 


\begin{tabular}{l|l|l|l}
$\begin{array}{l}\text { Case Reports in } \\
\text { Ophthalmology }\end{array}$ & $\begin{array}{l}\text { Case Rep 0phthalmol 2010;1:5-13 } \\
\text { D0I: } 10.1159 / 000313842\end{array}$ & Published online: May 12, 2010 & $\begin{array}{l}\text { ○ 2010 S. Karger AG, Basel } \\
\text { ISSN 1663-2699 } \\
\text { www.karger.com/cop }\end{array}$ \\
\hline
\end{tabular}

macrophages: The macrophages produce RANTES to suppress experimental autoimmune uveitis. J Immunol 2003;171:2652-2659. 